\title{
Vane shear strength of bio-improved sand reinforced with natural fibre
}

\author{
Mohsin Usman Qureshi ${ }^{1,{ }^{*}}$, Abdulsalam Al-Hilly ${ }^{1}$, Ola Al-Zeidi ${ }^{1}$, Ashwaq Al-Barrami ${ }^{1}$, and Ahed Al-Jabri ${ }^{1}$ \\ ${ }^{1}$ Sohar University, Faculty of Engineering, PO Box. 44, PC. 311, Sohar, Sultanate of Oman
}

\begin{abstract}
In the recent developments, bio-improvement has considerably enhanced the geotechnical properties and reduced degradation of loose desert sand without the environmental concerns. However, the effect of bio-improvement on sand weakens due to water submergence. Therefore, it is necessary to explore the techniques for retaining the strength of bio-improved sand in water submerged state. So, this paper reports the geotechnical performance of submerged bio-improved sand reinforced by discrete natural fibres. The desert sand sampled from Al-Sharqia Desert of Oman, bio-improved by xanthan gum and reinforced by discrete natural fibres obtained from date palm tree. Date palm fibres having a diameter less than $0.2 \mathrm{~mm}$ and length $1 \mathrm{~cm}$ were employed for sand reinforcement. Vane shear tests and standard compaction tests were performed on specimens having different mix ratios of sand-xanthan gum with and without natural fibres. The qualitative description of bio-improvement and fibre reinforcement effect on the desert sand is also presented as the photomicrographs taken by field emission scanning electron microscope. According to the results of strength tests at higher moisture content state, the discrete fibre reinforcement has enhanced the geotechnical performance of sand improved at lower concentrations.
\end{abstract}

\section{Introduction}

Sustainable development and rapidly increasing demand of environment-friendly infrastructure have motivated geotechnical engineers to innovate and develop unconventional engineered soil methods [1, 2]. In attempts to reduce or replace cement use in modern ground improvement practices, several alternatives such as geopolymers, alkali activated cement, geo-cement, and inorganic polymer concrete have been developed. However, recent attempts such as biological treatment of soils could attain the same engineering performance with less environmental concerns [3]. Biocementation shows potential to replace the energy intensive mechanical compaction processes or expensive and environmentally harmful chemical grouting [4]. Such techniques employ the biopolymers which are sustainable and environmentally-friendly materials because of their origin from natural resources. Among various types of biopolymers, xanthan gum has been commonly used in recent studies due to its appropriate strengthening efficiency and economic feasibility [5]. Biopolymers has been employed to enhance the geotechnical properties of geomaterial, such as to reduce the hydraulic conductivity of silty sand via pore filling $[6,7]$ to increase the undrained shear strength of soil by increasing the liquid limit [8], as a soil strengthener [5], to increase the unconfined compressive strength, cohesion, and stiffness of the sand treated with agar and modified starch [9], to enhanced durability of treated sand against slaking [10], increase in shear resistance and a reduction in the permeability of sand and silt [11], as temporary support and advanced undisturbed sampling [12].

The moisture sensitivity of the bio-treated sand is an important topic to be addressed. The elemental testing techniques may not work well to quantify the effect of moisture on the strength enhancement due to bioimprovement of geomaterial. In this study, the authors suggested to reinforce the bio-treated sand with natural fibres and experimentally delineate the moisture sensitivity of naturally reinforced bio improved sand.

\section{Materials and methods}

Desert sand is bio improved by using xanthan gum $[3,10]$ and reinforced with date palm fibre. The Vane shear strength of naturally reinforced bio-improved sand is delineated by vane shear tests at various moisture levels. The materials and equipment employed in the study are described below.

\subsection{Desert sand}

The desert sand (DS) used in this study is sampled from the Al-Sharqia desert of Oman [13]. The grain size distribution [14] of the sand is shown in Fig. 1. The desert sand is classified as poorly-graded fine sand (SP) according to the Unified Soil Classification System (USCS). The sand has a specific gravity [14] of $G_{s}=2.62$ and a fine content of $1.1 \%$. The standard proctor compaction test [15] gave a maximum dry density $\left(\gamma_{d}\right)$ of

\footnotetext{
* Corresponding author: mohsinqureshi81@,gmail.com
} 
$1.64 \mathrm{~g} / \mathrm{cm}^{3}$ at an optimum moisture content of $19.5 \%$. The photomicrograph taken by scanning electron microscope of DS indicates the particle shape with smooth surfaces lacking fines (Fig. 1), which are typical particulate characteristics of sand weathered and transported via aeolian processes in deserts [16].

\subsection{Natural fibre}

The soil reinforcement with natural fibres enhances the geotechnical properties, various types of fibres are in use such as coir fibre [17], palm fibre [18], jute [19] and barley straw [20]. The date palm fibres (Fig. 2) and available in abundance in Oman, so the present study employed them to reinforce the bio improved sand. The date palm fibres were randomly mixed in bio-improved sand $(0.2 \%$ by weight of sand $)$ having a diameter less than $0.2 \mathrm{~mm}$ and length $1 \mathrm{~cm}$.

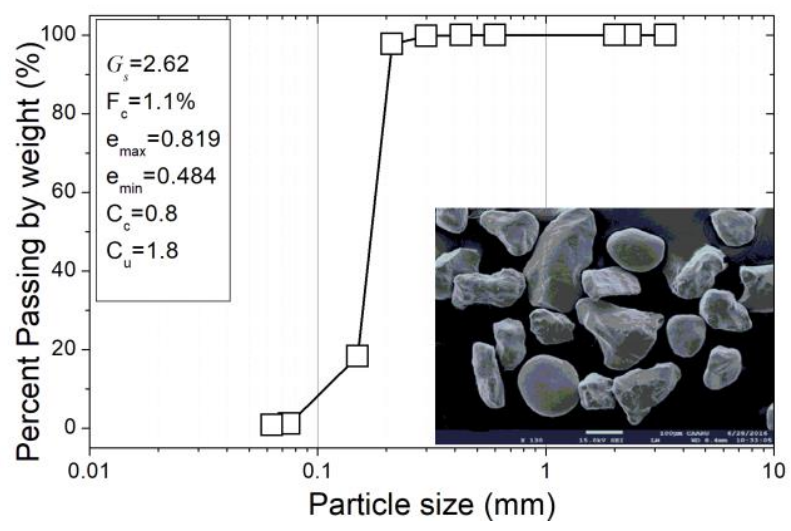

Fig. 1. Physical properties of desert sand (DS)

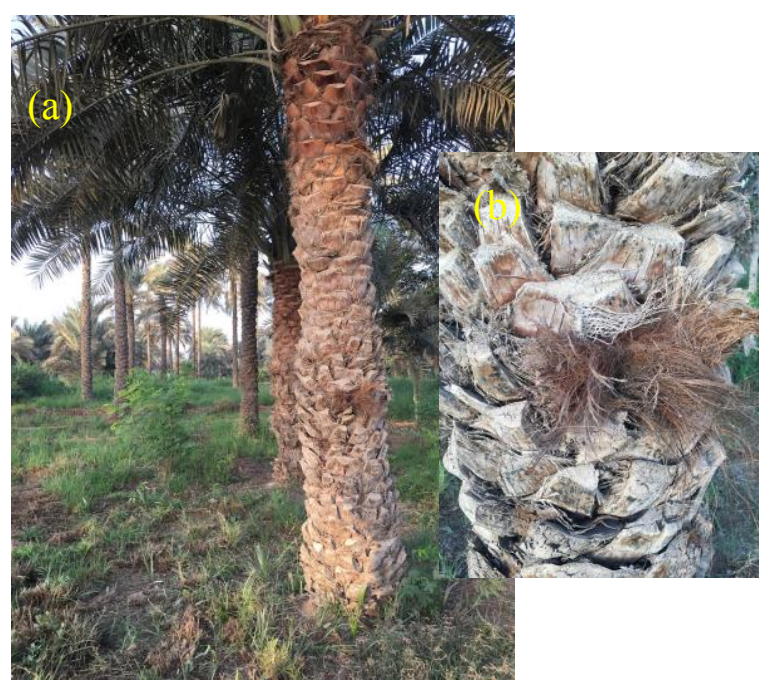

Fig. 2. (a) Date palm tree, (b) Natural fibre of date palm tree

\subsection{Xanthan gum}

Xanthan gum $\left(\mathrm{C}_{35} \mathrm{H}_{49} \mathrm{O}_{29}\right)$, has high viscous rheology and, is a natural anionic polysaccharide composed of Dglucuronic acid, D-mannose, pyruvylated mannose, 6-O- acetyl D-mannose, and a 1,4-linked glucan [21, 22] which is the most rigid biological repeating molecule [23]. The most well-known characteristics of Xanthan gum are pseudo plasticity [24] and high shear stability [25] even at low concentrations. Moreover, it has several desirable properties including, $\mathrm{pH}$ stability, storage stability, and ionic salt compatibility.

\subsection{Vane shear test}

The vane shear tests [26] are employed to determine the Vane shear strength of soil for near-zero confinements [27]. In the present study, vane shear (Fig. 3(a)) tests were performed using a 12.7-mm rectangular vane (Fig. 3(b)) (vane thickness $\mathrm{t}=0.3 \mathrm{~mm}$; area ratio $=9.7 \%$ ) on both untreated and bio-treated sand specimens reinforced with natural fibre, which had different initial moisture contents. Although the laboratory vane shear test presents problems with organic soils due to uncertain failure conditions around the vane circumference [28], three specimens were tested and averaged to represent a single soil condition with minimum uncertainty. The vane was pushed $50 \mathrm{~mm}$ into the soil from the top surface to place the blade directly in the middle of the specimens and then rotated at a constant rate of $10 \% \mathrm{~min}$ angular velocity [26]. The specimens were confined in a container having $10 \mathrm{~cm}$ diameter.

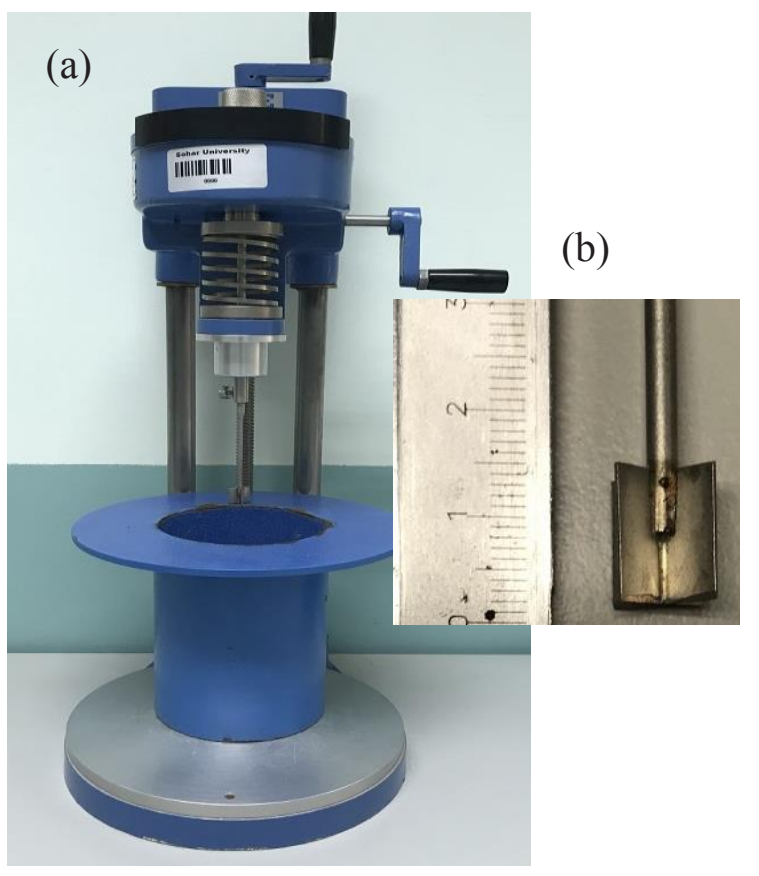

Fig. 3. (a) Vane shear test (VST) apparatus, (b) Vane

\subsection{Sample preparation}

The samples were prepared by mixing desert sand (DS), xanthan gum $(\mathrm{G})$ and date palm fibres $(\mathrm{F})$ at various ratios. Firstly, water was mixed with specified proportion of xanthan gum to make a gel and then sand, and fibres were added to produce the sample. Then the sample was 
transferred to the container for testing. The dry density of the samples was ranging from $1.3-1.5 \mathrm{~g} / \mathrm{cm}^{3}$. The detailed record of samples is shown in Table 1.

Table 1. Detail of samples

\begin{tabular}{|c|c|c|}
\hline Sample ID & $\begin{array}{c}\text { Xanthan gum } \\
(\mathbf{\%})\end{array}$ & $\begin{array}{c}\text { Fibre } \\
(\mathbf{\%})\end{array}$ \\
\hline DS & 0 & 0 \\
\hline DSG0.5 & 0.5 & 0 \\
\hline DSG1.0 & 1.0 & 0 \\
\hline DSG2.0 & 2.0 & 0 \\
\hline DSG3.0 & 3.0 & 0 \\
\hline DSG0.5F0.2 & 0.5 & 0.2 \\
\hline DSG1.0 F0.2 & 1.0 & 0.2 \\
\hline DSG2.0 F0.2 & 2.0 & 0.2 \\
\hline
\end{tabular}

\section{Results and discussions}

The standard proctor compaction tests [15] were performed on virgin sand DS, DSG1.0, DSG2.0 and DSG3.0 and the results are summarized in Fig. 4. The maximum dry density of DSG1.0 is $1.675 \mathrm{~g} / \mathrm{cm}^{3}$ and OMC is $13 \%$. The maximum dry density $\left(\rho_{d}\right)$ immediately increases with xanthan gum $1 \%$ treatment, while it decreases and becomes slightly lower than untreated sand at higher ( $\geq 2 \%$ ) xanthan gum content (Fig. 4).

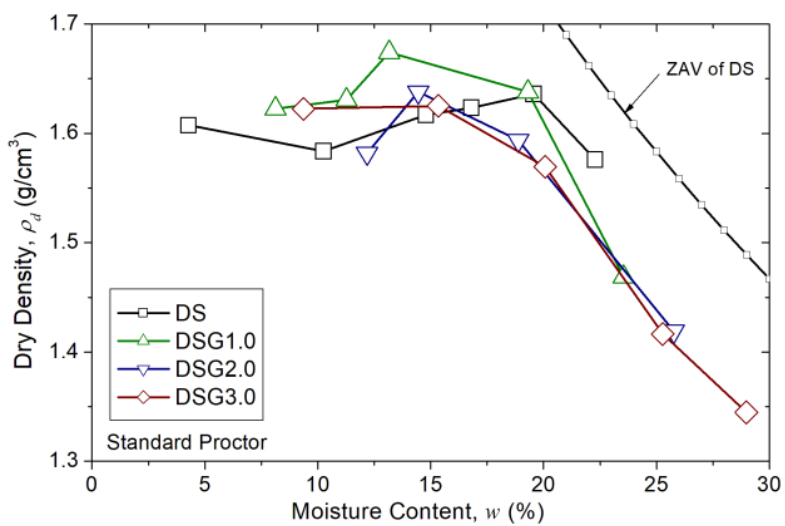

Fig. 4. Standard compaction test results of bio-improved desert sand

Meanwhile, optimum moisture content variation of xanthan gum-treated sands is consistent to the $\rho_{d}$ variation (Fig. 4), which shows the lowest value at the $1 \%$ xanthan gum-treated condition (DSG1.0), unfortunately data for $0.5 \%$ xanthan gum treatment is not available but expected to have higher $\rho_{d}$ as compared to $1 \%$ xanthan gum treatment. The results for laboratory vane shear strength of virgin sand and xanthan gum-treated sand at various water contents are shown in Fig. 5. The vane shear strength $\left(\tau_{\mathrm{v}}\right)$ increased with a reduction in the initial water content (Fig. 5) for xanthan gum treated sand, however, further reduction in initial water content of virgin sand reduced its strength.

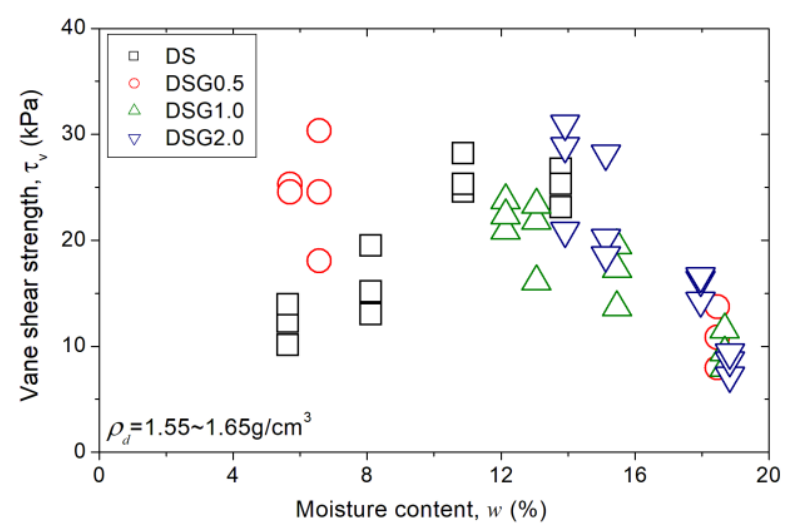

Fig. 5. Vane shear strength of bio-treated desert sand at different moisture contents

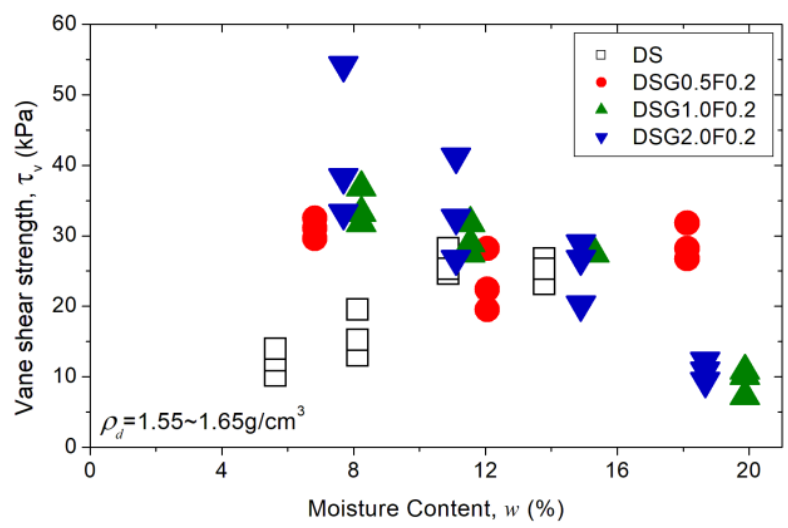

Fig. 6. Vane shear strength of reinforced bio-treated desert sand at different moisture contents 

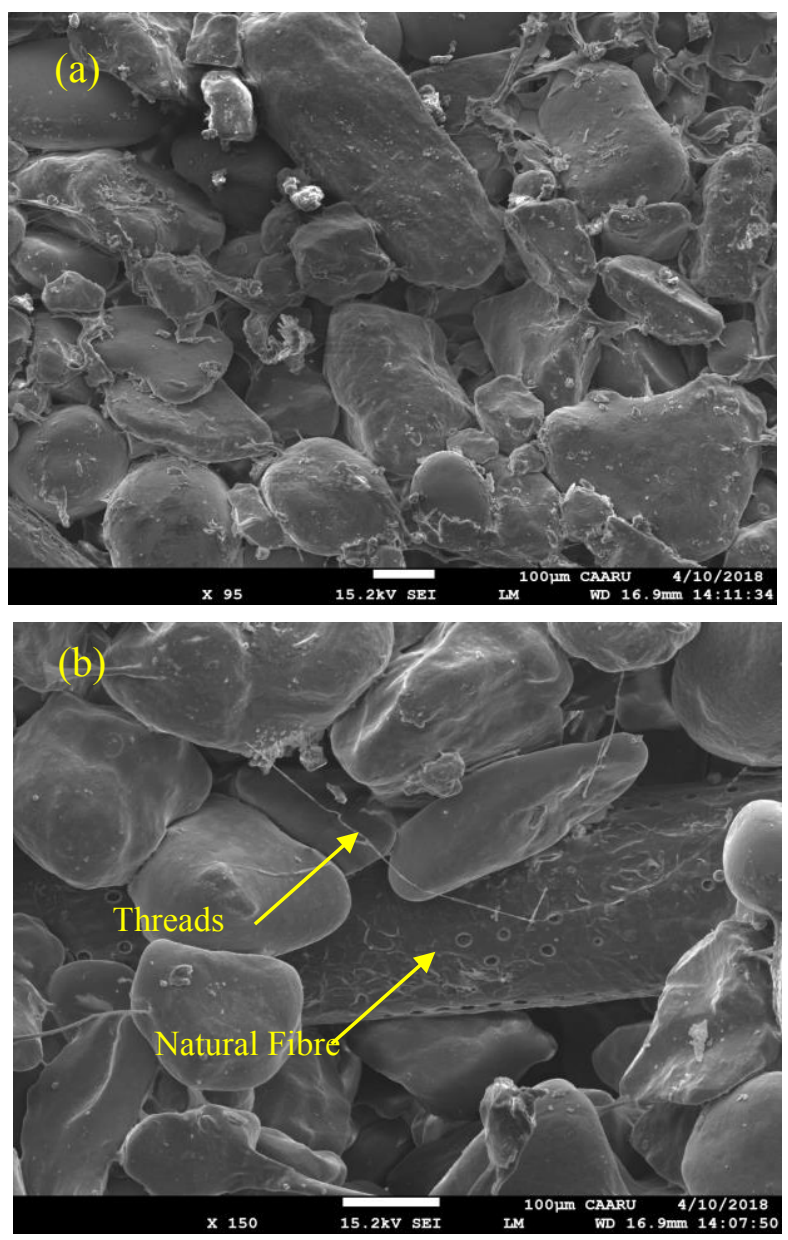

Fig. 7. (a) Bio-improved desert sand, (b) Bio-improved desert sand reinforced with natural fibre

The vane shear strength $\left(\tau_{\mathrm{v}}\right)$ of virgin sand and xanthan gum treated sand reinforced with natural fibres is plotted against moisture content as shown in Fig. 6. The trend of reduction in strength of natural fibre reinforced xanthan gum treated sand due to the increase in moisture content is the same for $1 \%$ and $2 \%$ gum treatments, however $0.5 \%$ gum treatment showed a different behaviour (Fig. 6). The strength of DSG0.5F0.2 sample decreased up to the $12 \%$ moisture content, and then starts to increase upon further increase of moisture content. However, in the case of other samples, $1 \%$ and $2 \%$ treatments, strength continued to decrease up on increasing moisture content, even being reinforced with natural fibre. So, this suggests that the sand treated with $0.5 \%$ xanthan gum can retain strength at high moisture contents if reinforced with $0.2 \%$ natural fibre.

The photomicrographs of biopolymer-treated sand at a concentration of $0.5 \%$ xanthan gum shown in Fig. 7(a) reveals that the biopolymer accumulated between the spaces of particles and bound them. The strength of biopolymer treated sand depends on the strength of the xanthan gum matrices and threads existing in the pore space. However, this bond is lost upon hydration of xanthan gum matrix with increase in moisture content. The contribution of natural fibre to reinforce the biotreated sand can be seen in Fig. 7(b). The natural fibre provides support to the deformed biotreated sand having high moisture content.

\section{Conclusions}

The bio-improvement can significantly improve the strength of sand; however, the strength reduces upon interaction with water. This reduction in strength can be improved by reinforcing with natural fibre. The reinforcement is only successful at a lower concentration of biopolymer. At the higher concentrations of biopolymer, the water hydrates the biopolymer and the peak shear resistance is lost along with the support of the natural fibre reinforcement is compromised.

The research described in this paper was supported by the Faculty of Engineering and the participation in the conference is supported by the Research Development Incentives at Sohar University Oman.

\section{References}

1. J. T. DeJong, M. B. Fritzges, K. Nusslein, J. Geotech. Geoenv. Eng., 132, 11, 1381-1392 (2006)

2. J. Mitchell, J. Santamarina, J. Geotech. Geoenv. Eng., 131, 10, 1222-1233 (2005)

3. M.U. Qureshi, I. Chang, K. Al-Sadarani, Geomech. Eng., 12, 5, 785-801 (2017)

4. V. Ivanov, J. Chu, Rev. Env. Sci. Biotech., 7, 2, 139153 (2008)

5. I. Chang, J. Im, A. K. Prasidhi, G.-C. Cho, Constr. Build. Mater., 74, 65-72 (2015)

6. A. Bouazza, W. P. Gates, P. G. Ranjith, Géotechnique, 59, 1, 71-72 (2009)

7. R. Khachatoorian, I. G. Petrisor, C. C. Kwan, T. F. Yen, J. Petrol. Sci. Eng., 38, 1-2, 13-21 (2003)

8. R. A. Nugent, G. P. Zhang, R. P. Gambrell, Trans. Res. Rec., 2101, 34-43 (2009)

9. H. R. Khatami, B. C. O'Kelly, J. Geotech. Geoenv. Eng., 139, 8, 1402-1406 (2012)

10. M. Qureshi, S. Al-Qayoudhi, S. Al-Kindi, A. AlHamdani, K. Al-Sadrani, Int. J. Sci. Eng. Res., 6, 11, 486-490 (2015)

11. M. K. Ayeldeen, A. M. Negm, M. A. El Sawwaf, Arab. J. Geosc., 9, 5, 1-13 (2016)

12. K. G. Sutterer, J. D. Frost, J. L. A. Chameau, J. Geot. Eng., 122, 3, 209-215 (1996)

13. P. P. Pease, V. P. Tchakerian, Ann. Assoc. Am. Geogr., 92, 3, 416-434 (2002)

14. British Standards, I. BS 1377-2 Methods of test for soils for civil engineering purposes. Classification tests, British Standards Institution, London (1990)

15. British Standards, I. BS 1377-4 Methods of test for soils for civil engineering purposes/ Compactionrelated tests, British Standards Institution, London (1990)

16. F. I. Khalaf, I. M. Gharib, Sediment. Geol., 45, 1, 147-158 (1985) 
17. S. Babu, K. Vasudevan, J. Mater. Civ. Eng., ASCE, 20, 571-7 (2008)

18. M. Marandi, H. Bagheripour, R. Rahgozar, H. Zare, Am. J. Appl. Sci., 5, 209-20 (2008)

19. P. Aggarwal, B. Sharma In: Proc of int conf on adva in civ eng, Trabzon, Turkey; 27-30 September, (2010)

20. T. Ashour, A. Bahnasawey, W. Wu, AJAE, 1, 86-92 (2010)

21. F. Garcia-Ochoa, V. E. Santos J. A. Casas, E. Gomez, Biotech. Adv., 18, 7, 549-579 (2000)

22. R. A. Hassler, D. H. Doherty, Biotech. Prog., 6, 3, 182-187 (1990)

23. N. P. Yevlampieva, G. M. Pavlov, E. I. Rjumtsev, Int. J. Biol. Macromol., 26, 4, 295-301 (1999)

24. M. Milas, M. Rinaudo, Carb. Res., 158, 191-204 (1986)

25. C. S. H. Chen, E. W. Sheppard, Polym. Eng. Sci., 20, 7, 512-516 (1980)

26. British Standard Institute BS 1377-7: Methods of test for soils for civil engineering purposes. Shear strength tests (total stress). British Standard Institute (1990)

27. R.J. Chandler, In Vane shear str test soils: field and lab stu. ASTM Int (1988)

28. A. O. Landva, Can. Geotech. J., 17, 1, 1-19 (1980) 